NASA/TM-2003-212378

\title{
Comparison of Tone Mode Measurements for a Forward Swept and Baseline Rotor Fan
}

Laurence J. Heidelberg

Glenn Research Center, Cleveland, Ohio 
Since its founding, NASA has been dedicated to the advancement of aeronautics and space science. The NASA Scientific and Technical Information (STI) Program Office plays a key part in helping NASA maintain this important role.

The NASA STI Program Office is operated by Langley Research Center, the Lead Center for NASA's scientific and technical information. The NASA STI Program Office provides access to the NASA STI Database, the largest collection of aeronautical and space science STI in the world. The Program Office is also NASA's institutional mechanism for disseminating the results of its research and development activities. These results are published by NASA in the NASA STI Report Series, which includes the following report types:

- $\quad$ TECHNICAL PUBLICATION. Reports of completed research or a major significant phase of research that present the results of NASA programs and include extensive data or theoretical analysis. Includes compilations of significant scientific and technical data and information deemed to be of continuing reference value. NASA's counterpart of peerreviewed formal professional papers but has less stringent limitations on manuscript length and extent of graphic presentations.

- TECHNICAL MEMORANDUM. Scientific and technical findings that are preliminary or of specialized interest, e.g., quick release reports, working papers, and bibliographies that contain minimal annotation. Does not contain extensive analysis.

- CONTRACTOR REPORT. Scientific and technical findings by NASA-sponsored contractors and grantees.
- CONFERENCE PUBLICATION. Collected papers from scientific and technical conferences, symposia, seminars, or other meetings sponsored or cosponsored by NASA.

- SPECIAL PUBLICATION. Scientific, technical, or historical information from NASA programs, projects, and missions, often concerned with subjects having substantial public interest.

- TECHNICAL TRANSLATION. Englishlanguage translations of foreign scientific and technical material pertinent to NASA's mission.

Specialized services that complement the STI Program Office's diverse offerings include creating custom thesauri, building customized databases, organizing and publishing research results ... even providing videos.

For more information about the NASA STI Program Office, see the following:

- Access the NASA STI Program Home Page at http://www.sti.nasa.gov

- E-mail your question via the Internet to help@sti.nasa.gov

- Fax your question to the NASA Access Help Desk at 301-621-0134

- Telephone the NASA Access Help Desk at 301-621-0390

- Write to:

NASA Access Help Desk

NASA Center for AeroSpace Information 7121 Standard Drive

Hanover, MD 21076 
NASA/TM-2003-212378

\section{Comparison of Tone Mode Measurements for a Forward Swept and Baseline Rotor Fan}

Laurence J. Heidelberg

Glenn Research Center, Cleveland, Ohio

Prepared for the

Nineth Aeroacoustics Conference and Exhibit cosponsored by the American Institute of Aeronautics and Astronautics and the Confederation of European Aerospace Societies

Hilton Head, South Carolina, May 12-14, 2003

National Aeronautics and

Space Administration

Glenn Research Center 


\section{Acknowledgments}

Daniel Sutliff, SEST, Inc., wrote the data reduction and acquisition programs used in this investigation under contract NAS3-00170.

This report is a formal draft or working paper, intended to solicit comments and ideas from a technical peer group.

Available from

NASA Center for Aerospace Information 7121 Standard Drive

Hanover, MD 21076
National Technical Information Service 5285 Port Royal Road Springfield, VA 22100

Available electronically at http:/ /gltrs.grc.nasa.gov 


\title{
COMPARISON OF TONE MODE MEASUREMENTS FOR A FORWARD SWEPT AND BASELINE ROTOR FAN
}

\author{
Laurence J. Heidelberg* \\ National Aeronautics and Space Administration \\ Glenn Research Center \\ Cleveland, Ohio 44135
}

\begin{abstract}
A forward swept fan, designated the Quite High Speed Fan (QHSF), was tested in the NASA Glenn 9- by 15-foot Low Speed Wind Tunnel to investigate its noise reduction relative to a baseline fan of the same aerodynamic performance. The design objective of the QHSF was a $6 \mathrm{~dB}$ reduction in Effective Perceived Noise Level relative to the baseline fan at the takeoff condition. The design noise reduction was to be a result of lower levels of multiple pure tone noise due to the forward swept rotor, and lower rotor/stator interaction tone noise from a leaned stator. Although the design $6 \mathrm{~dB}$ reduction was observed in far-field measurements, the induct mode measurements revealed the reasons for this reduction were not the ones related to the design goals. All of the noise reduction was from the blade passing tone and its harmonics and most of this was unexpectedly from rotor/strut interaction modes. The reason for large differences in rotor/strut noise sources could not be determined with certainty. The reductions in the multiple pure tone noise for the forward swept rotor were not observed.
\end{abstract}

\section{INTRODUCTION}

The NASA Advance Subsonic Technology program has an ongoing noise reduction element to provide the technology to meet increasingly restrictive airport noise regulations. As part of this effort a forward swept rotor fan was designed and constructed by Honeywell Engines and Systems for the purpose of reducing the noise of supersonic tip speed fans. This 22inch diameter fan, designated the Quiet High Speed Fan (QHSF), was tested in the NASA Glenn 9- by 15-foot Low Speed Wind Tunnel to investigate its noise reduction characteristics. In addition, a model of an existing conventional modern fan was also tested to provide a baseline for the purpose of comparison. The baseline fan incorporates many currently used noise reduction features. This paper will present measurements of both inlet and exhaust duct modes for the Blade Passing Frequency (BPF) and $2 \mathrm{BPF}$ tones in terms of PWL. In addition, the modal structure of the Multiple Pure Tones (MPT) in the inlet is presented.

\section{APPARATUS AND PROCEDURE}

Baseline Fan

The baseline fan is a 22-inch model of the fan used on the Honeywell TFE731-60 engine. This fan consists of a moderately aft swept rotor and an aft swept set of stator vanes. The baseline fan already has considerable acoustic design input. Blade/vane ratio, rotor-stator spacing and vane sweep were chosen with noise reduction in mind. A photograph of the baseline fan, with the fan case removed to better view the rotor and stator is shown in figure 1 . Table 1 shows the stage design characteristics for both the baseline fan and QHSF. The design, takeoff, cutback, and approach tip speeds in feet/sec (and tip rotational Mach Number) are 1472 (1.32), 1328 (1.19), 1111 (0.99), and 868 (0.78) respectively.

Quiet High Speed Fan

The QHSF was designed to have the same aerodynamic performance as that of the baseline fan (table 1) but with reduced noise. The acoustic design objective was a $6 \mathrm{~dB}$ reduction in perceived noise level relative to the baseline fan at takeoff condition. This noise reduction was to consist of reductions in MPT and rotor/stator interaction noise. The MPT noise is generally attributed to pressure disturbances from the shock structure on the rotor. The QHSF incorporates forward sweep on the rotor to reduce the relative velocity component normal to the blade leading edge to subsonic levels. The intent of this sweep is to eliminate the formation of the inlet shock and thus achieve MPT noise reduction. The goal of this rotor blade design was to contain any remaining shocks within the passage. This goal could not be meet for all radial locations and rotor speeds but over a wide enough range so as to predict significant MPT reduction. A photograph of the QHSF with the fan case removed is shown in figure 1 . The 50 degree forward sweep at the rotor tip is apparent.

One way to reduce rotor/stator interaction noise is to make the intersection of rotor blade wake the leading edge of the stator vane and the as close as possible to perpendicular. This lowers the trace speed of the wake intersection with the vanes in the circumferential direction, and causes multiple intersections per vane

*Senior Research Engineer, Senior Member AIAA. 
(phase cancellations). The QHSF employs significant lean to reduce rotor/stator interaction noise. Figure 2 compares photographs of the two vane sets to illustrate the difference in lean. The QHSF vanes have a 30 degrees lean at the tip while the baseline vanes have little lean. Reference 1 provides a more complete description of the QHSF design.

\section{Aerodynamic Operation and Performance}

The baseline and QHSF fans were operated so that they had the same bypass ratio speed line as the TFE 731-60 engine. A complete description of the model fan operation and performance can be found in reference 2 . The goal was to reduce fan noise while matching, or improving, the performance capability of the baseline fan with respect to fan pressure ratio, mass flow, efficiency, and operability margin. The QHSF shows improved performance in most respects relative to the baseline fan, however, a part speed instability reduces operability margins to insufficient levels. The new fan stage had a design point peak adiabatic efficiency of $87.1 \%$ compared to $83.7 \%$ for the baseline fan. The operating line pressure rise at design point rotational speed was 1.770 and 1.755 for the QHSF and baseline fans, respectively. Weight flow at design point is 98.28 for the QHSF and $97.97 \mathrm{lbm} / \mathrm{sec}$ for the baseline fan. Unfortunately, the operability margins for the QHSF approached $0 \%$ at the part speed operating conditions near $75 \%$ speed. The baseline fan maintained sufficient margin throughout the operating range. Based on the stage performance measurements, this concept shows promise for improved performance over current technology if the operability limits can be solved.

\section{Acoustic Mode Measurements}

A continuously rotating microphone technique described in references 3 and 4 was used. The mode measurement system installed on the inlet is shown in figure 3 . The same system installed in the fan exhaust is shown in figure 4 . The rotating rake uses a control system slaved to the fan shaft to rotate at exactly $1 / 200$ th of the fan speed as if it were geared to the fan shaft. In the rotating frame of reference, each spinning circumferential mode order is Doppler shifted inversely proportional to its spin rate. Thus, each circumferential order is separated by 0.005 shaft orders in frequency. The radial order is determined by a least squares curve fit using the basis functions from the hard wall boundary condition of the Bessel's equation of all radial orders that might be expected, to the measured complex radial profile. In order to resolve the highest radial order that can propagate in the inlet, at 2BPF, 14 radial measurements were used, while only 8 were needed in the exhaust. These microphone signals are brought across the rotating frame by FM telemetry.

Several improvements in this mode measurement technique have been made since its first implementation reported in references 5 to 7 . These improvements were developed during tests on a large low speed fan rig (Active Noise Control Fan (ANCF)). The improvements involve the installation of aluminum foam windscreens over the microphones to lower selfnoise, thus improving signal to noise ratio and additional foam shields on the exhaust rake (fig. 4) to attenuate the effects of the residual rotor wake interaction with the microphones. The locations of the mode measurement planes are also shown in figure 5 . The inlet measurements were taken at the throat (minimum diameter). The exhaust measurements were taken in a plane just inside the nozzle exit.

\section{Test Conditions}

The fan models were run in the NASA Glenn 9- by 15-foot Low Speed Wind Tunnel at a Mach number of 0.10 . The fan was operated at 11 different speeds for the mode measurements, as shown in Table 2 that include nominal, approach, cutback, and takeoff conditions. A slightly larger nozzle exit area was used for exhaust measurements to compensate for rake blockage. All tests were run with ducts in a hard wall (no acoustic treatment) configuration.

\section{RESULTS AND DISCUSSION}

The complete modal structure (circumferential and radial orders) for BPF and $2 \mathrm{BPF}$ were measured. Both inlet and exhaust duct modes are presented in terms of sound power, PWL, referenced to $10^{-12}$ watts. An example of the BPF modal structure for the exhaust is shown in figure 6 in the form of a 3-D bar graph. This figure is for the baseline fan at cutback power. The mode orders are displayed on the horizontal axes, and the power on the vertical axis. The back row represents the sum of the radial orders in each circumferential (m) order. This m-order power will be used to comparing the two fans for most of this report due to its simplicity. The rotor/strut interaction $\mathrm{m}$ orders are easily seen standing well above the extraneous modes (other than rotor/stator interaction modes). There are 10 struts in this fan, thus the interaction orders are 10 orders apart $(\mathrm{m}=12,2,-8,-18)$. There are no rotor/stator interaction modes present for either fan at BPF due to their blade/vane ratio. Table 3 lists all the expected circumferential mode orders for both fans classified by source.

The mode results will be presented in the following order: the inlet 1 and 2 BPF, the exhaust 1 and 2 BPF and finally the inlet MPT.

\section{Inlet Mode Power}

A comparison of the QHSF to the baseline fan at the Blade Passing Frequency (BPF) tone is shown in figure 7. This plot shows the sum of all the strut interaction modes, the rotor locked mode $(\mathrm{m}=22)$, and total tone power as a function of fan speed. The rotating rake mode measurement used in this investigation can 
suffer from interference due to the wake of the rake for the case of the inlet rotor locked mode $(m=22)$. A discussion of this problem is presented in reference 8 . When the $m=22$ mode is sufficiently stronger then this interference the measurement is accurate. In this case, PWL levels of approximately $125 \mathrm{~dB}$ are sufficiently high. There are no dramatic differences between the fans for this tone. The very rapid rise in tone power above 12,000 RPM is due to the rotor locked field, $m=22$ cutting on. Figure 8 shows this same comparison at $2 \mathrm{BPF}$. In addition to the modes shown at $\mathrm{BPF}$, the rotor/stator interaction $\mathrm{m}$ order $(\mathrm{m}=-8)$ is cuton here, although it is generally below the $100 \mathrm{~dB}$ minimum of the plot. The trend in total tone power over the speed range is for the QHSF (forward swept rotor) to be a few $\mathrm{dB}$ lower. This trend is mostly due to the strut modes being lower for the QHSF, and at the higher speeds the $\mathrm{m}=44$ rotor locked mode is generally lower also. It would not be expected that 1 and 2BPF tone power differences between fans would be as great in the inlet as in the exhaust since, the rotor transmission loss tends lower aft interaction sources relative to other sources. This is particularly true for the $2 \mathrm{BPF}$ rotor/stator interaction, which is a counterrotating $\mathrm{m}$ order $(\mathrm{m}=-8)$.

\section{Exhaust Mode Power}

A comparison of the modal power for the two fans at $\mathrm{BPF}$ is shown in figure 9. The QHSF has significantly lower total tone power then the baseline fan for most of the speed range. The primary reason for this is the enormous difference in the rotor/strut interaction modes. Differences of over $20 \mathrm{~dB}$ are seen in the strut mode power. The reason for these differences are not known but speculations as to the cause can be grouped into two categories; 1) weaker and or more leaned QHSF rotor wakes, 2) wakes weakened and or more modified by the QHSF stator. One wonders if the rotor/strut interaction levels for the baseline fan are unusually large and the difference between fans is thus exaggerated. Another mode where huge differences are seen is the $\mathrm{m}=22$ rotor/stator interaction. Here the difference between fans approaches $25 \mathrm{~dB}$. Possible explanations for this could be weaker QHSF rotor wakes (longer rotor/stator spacing at the tip) or perhaps more likely the greater lean of the QHSF stator vane at the tip (fig. 2).

The 2BPF comparisons are shown in figure 10. The total tone power for the QHSF is generally $5 \mathrm{~dB}$ lower then the baseline fan over the full speed range. This is primarily a result of the reduced levels of the rotor/stator interaction mode, $\mathrm{m}=-8$ in the QHSF. These levels are 7 to $14 \mathrm{~dB}$ lower for QHSF. Differences in the strut modes in favor of QHSF of 1 to $10 \mathrm{~dB}$ also contribute a small amount to the overall difference. Just as with the $m=22$ at BPF the $m=44$ at $2 \mathrm{BPF}$ rotor/stator interaction is generally much lower for the QHSF. Just as with the BPF results, the $2 \mathrm{BPF}$ results the longer tip spacing of the swept rotor, and the extreme lean of the stator at the tip are likely causes of this benefit. In recent tests (as yet unpublished) the baseline rotor was run with the QHSF stator. Far-field results indicated tone noise levels similar to those of the QHSF. This indicates the leaned stator is probably responsible for much of the rotor/strut and rotor /stator source noise reductions in the QHSF.

\section{Multiple Pure Tones}

The MPT power distribution in the inlet, at five different speeds is shown in figure 11. Shaft orders from 1 to 22 are presented, although the order 22 is the $\mathrm{BPF}$ tone, it is included for reference. Both fans have similar power distributions, considering that the individual tones are related to blade to blade manufacturing differences. There appears to be a trend in the power distributions, for the maximum power to occur near the low end of the propagating shaft orders (near cutoff).

The sum of the power for all the shaft orders of the MPT was called MPT power and is shown in figure 12(a) for the supersonic rotational tip speed range. The baseline fan has a slight advantage over the QHSF but not over the full range of speed. This MPT power levels for the QHSF seems disappointing in light of the design goals. It was always recognized that the blade shock could not be swallowed for the full speed range of fan speed but, at least, there might be an advantage at the low supersonic tip speeds. This was not the case as shown in figure 12(a), but the swept rotor (QHSF) was slightly higher in MPT power at the low supersonic speeds. Figure 12(b) shows the comparison of the two fans when the MPT power is added to the BPF power. The motivation for this plot is the similar nature of these sources, rotor locked modes. The nearly linear relation between rotor speed and power is interesting. Since the inlet BPF tone (mode) is a result of the 22 blade direct aerodynamic field of the rotor, perhaps the MPT sources should be viewed in the similar way as the FFT of the complete field.

\section{CONCLUDING REMARKS}

Although the design noise reduction goal for the QHSF of $6 \mathrm{~dB}$ in EPNL was meet at takeoff (ref. 9), unexpectedly the reduction seems to come mostly from the 1 and $2 \mathrm{BPF}$ tones and not the MPT. The mode measurements show the vast majority of these reductions come from rotor/strut interaction. The QHSF was expected to reduce rotor/stator interaction noise and it did but, both the reductions of this source and the rotor/strut source seems unusually large (20 to $24 \mathrm{~dB}$ in places). One wonders, if these very large reductions might, in part, be a result of the baseline fan being somewhat noisier then expected, especially in regard to the rotor/strut interaction source. Recent tests of the combination of the baseline rotor and QSHF (leaned) 
stator indicate the stator may be responsible for the large rotor/strut noise reduction. While the reductions in 1 and $2 \mathrm{BPF}$ tone power level are impressive, the expected significant reductions in MPT levels for the QHSF in this investigation were not observed.

\section{REFERENCES}

1. Weir, Donald, "Design and Test of Fan/Nacelle Models, Quiet High-Speed Fan, Final Report," NASA CR-212370, April 2003.

2. Fite, E.B., "Overall Aerodynamic Performance Measurements for a Forward Swept Low Noise Fan," NASA TM (to be published in 2003).

3. Heidelberg, L.J., and Hall, D.G., "Acoustic Mode Measurements in the Inlet of a Model Turbofan Using a Continuously Rotating Rake," Journal of Aircraft. 32, No. 4, 1995, pp.761-767.

4. Hall, D.G. et al., "Acoustic Mode Measurements in the Inlet of a Model Turbofan Using a Continuously Rotating Rake: Data Collection/ Analysis Techniques," AIAA-93-0599, NASA TM-105936, January 1993.
5. Heidelberg, L.J., et al., "A Unique Ducted Fan Test Bed for Active Noise Control and Aeroacoustics Research," AIAA Paper 96-1740, May 1996; also NASA TM-107213.

6. Sutliff, D.L., Nallasamy, M., Heidelberg, L.H., Elliott, D.M., "Baseline Acoustic Levels of the NASA Active Noise Control Fan Rig," AIAA Paper 96-1745, May 1996; also NASA TM-107214.

7. Heidelberg, L.J., and Elliot, D.M., "A Comparison of Measured Tone Modes for Two Low Noise Propulsion Fans," AIAA-2000-1989, June 2000; also NASA/TM-2000-210231.

8. Heidelberg, L.J., "Fan Noise Source Diagnostic Test-Tone Modal Structure Results," AIAA Paper 2002-2428, June 2002; also NASA/ TM-2002-211594.

9. Dittmar, J.H., et al. "The Noise of a Forward Swept Fan,” NASA/TM-2003-212208, April 2003.

Table 1. Fan design parameters at fan aero design point for 22-inch diameter fan (baseline and QHSF)

\begin{tabular}{|l|c|}
\hline \multicolumn{1}{|c|}{ Parameter } & Value \\
\hline Corrected weight flow, $\mathrm{lbm} / \mathrm{sec}$ & 98.9 \\
\hline Corrected weight flow per unit area, $\mathrm{lbm} / \mathrm{sec} / \mathrm{ft}^{2}$ & 42.7 \\
\hline Tip speed, ft/sec & 1474 \\
\hline Bypass ratio & 3.83 \\
\hline Overall pressure ratio & 1.82 \\
\hline Adiabatic efficiency, overall, \% & 89.5 \\
\hline Fan hub/tip ratio & 0.35 \\
\hline Rotor blade count & 22 \\
\hline Stator vane count & 52 \\
\hline
\end{tabular}

Table 2. Fan test points

\begin{tabular}{|l|c|c|}
\hline Fan corrected rpm & Fan corrected tip speed, ft/sec & Fan tip rotational Mach No. \\
\hline 8516 & 817 & 0.731 \\
\hline 9039 (approach) & 868 & 0.777 \\
\hline 9510 & 913 & 0.817 \\
\hline 10646 & 1022 & 0.915 \\
\hline 11150 & 1070 & 0.958 \\
\hline 11572 (cutback) & 1111 & 0.995 \\
\hline 12500 & 1200 & 1.074 \\
\hline 13342 & 1281 & 1.147 \\
\hline 13831 (takeoff) & 1328 & 1.189 \\
\hline 14500 & 1392 & 1.246 \\
\hline 15000 & 1440 & 1.289 \\
\hline
\end{tabular}

Table 3. Circumferential mode orders for fans cut-on at the highest speed

\begin{tabular}{|c|c|c|}
\hline Harmonic & Rotor (22)/stator(52) & Rotor(22)/strut(10) \\
\hline $1 \mathrm{BPF}$ & 22 & $-32,-28,-18,-8,2,12,22$ \\
\hline $2 \mathrm{BPF}$ & $-8,44$ & $-56,-46,-36,-26,-16,-6,4,14,24,34,44,54,64$ \\
\hline
\end{tabular}




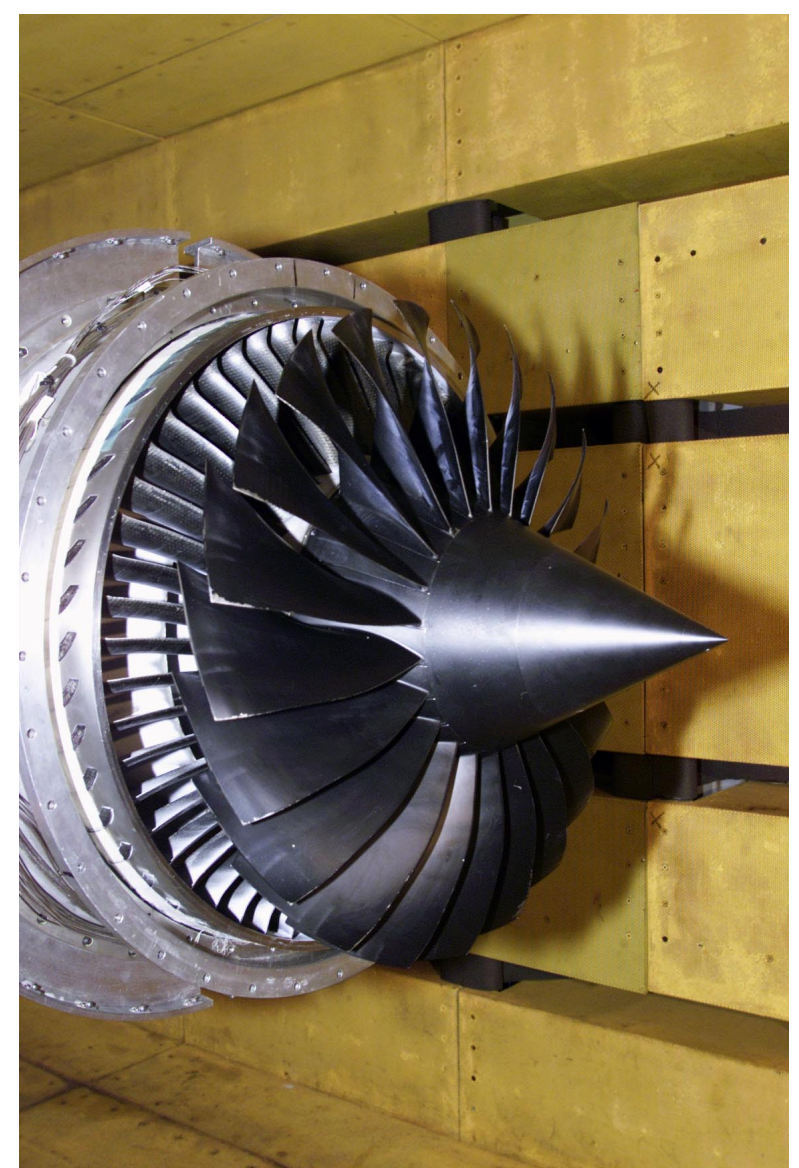

Baseline

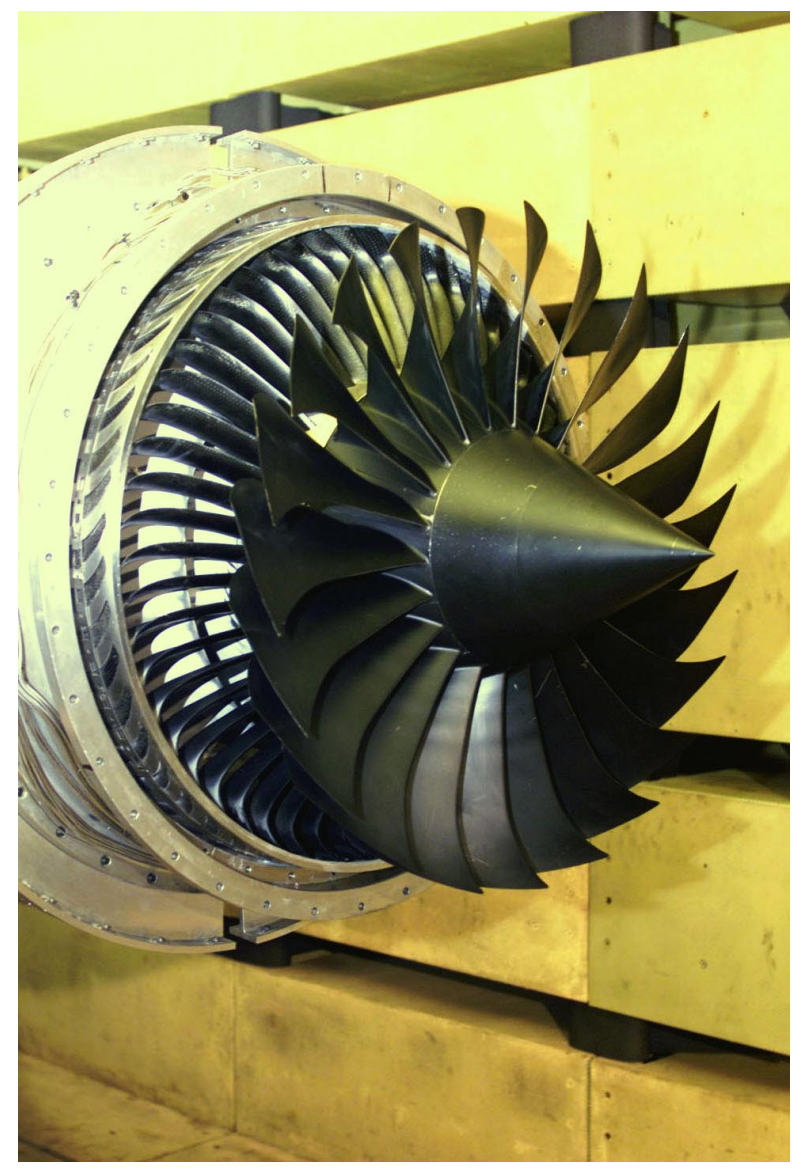

Quiet High-Speed

Figure 1. Photographs of the model fans with their casings removed. 

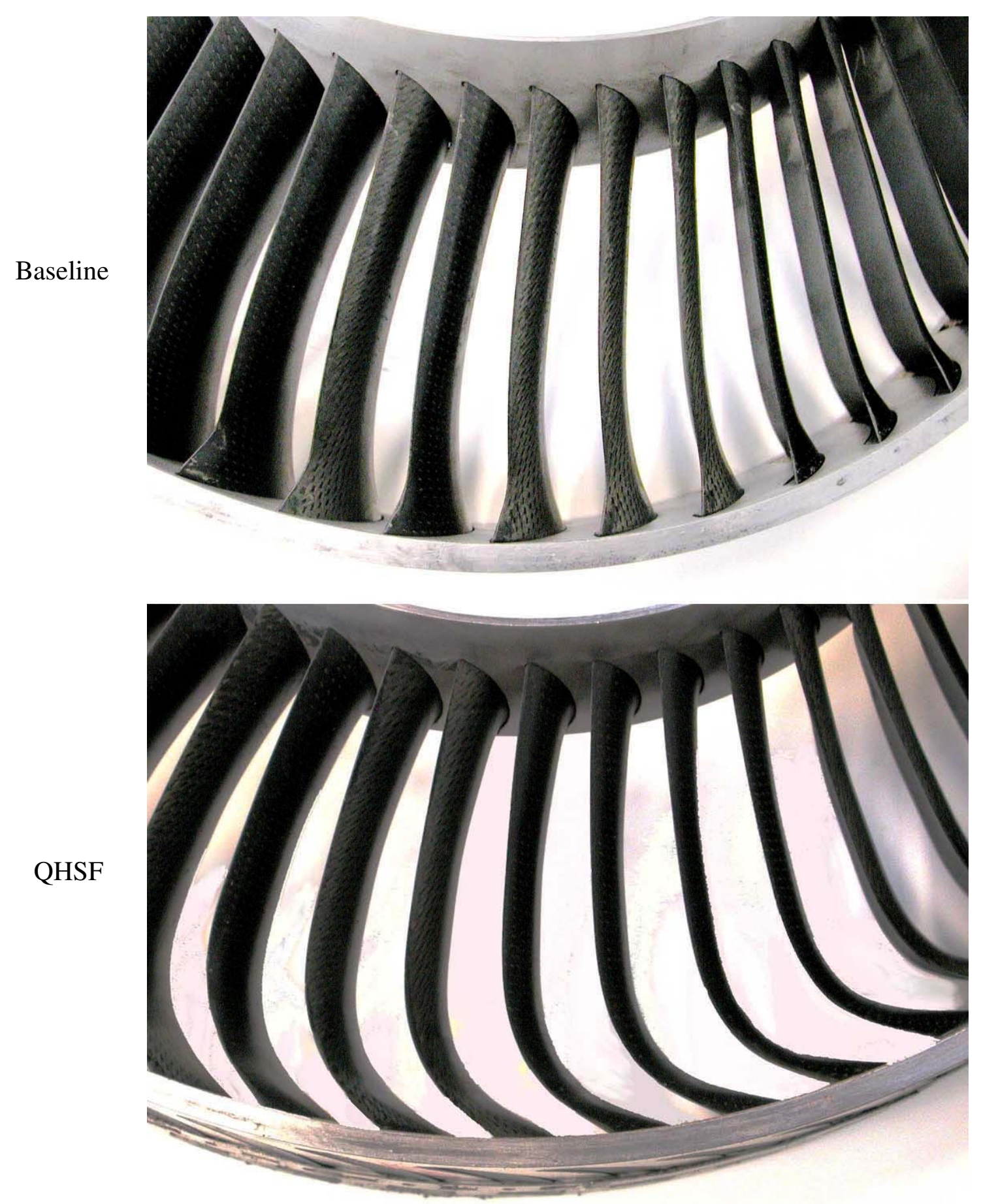

Figure 2. Photographs of the stators of the model fans. 


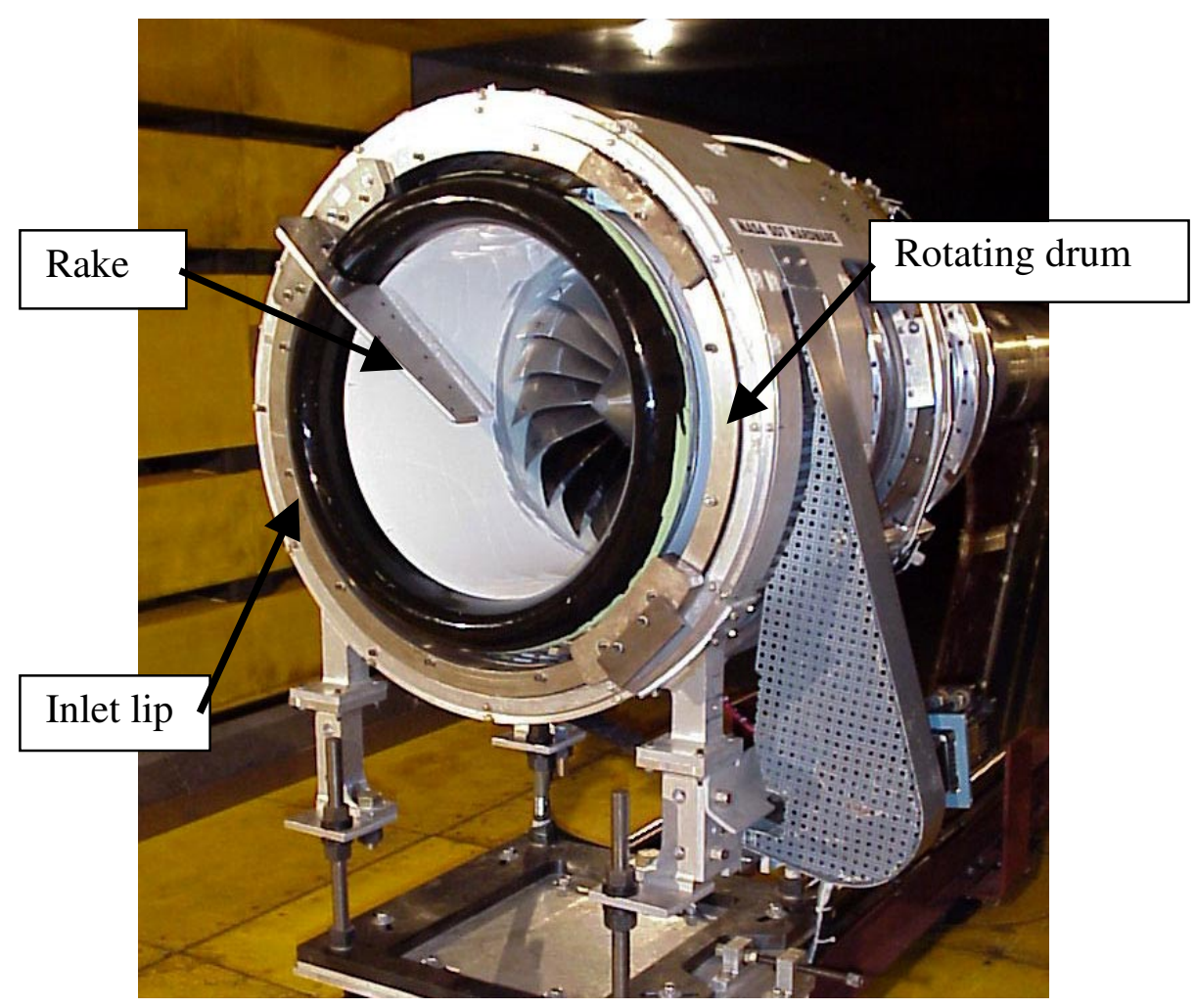

Figure 3. Mode measurement system installed on the inlet of the QHSF.

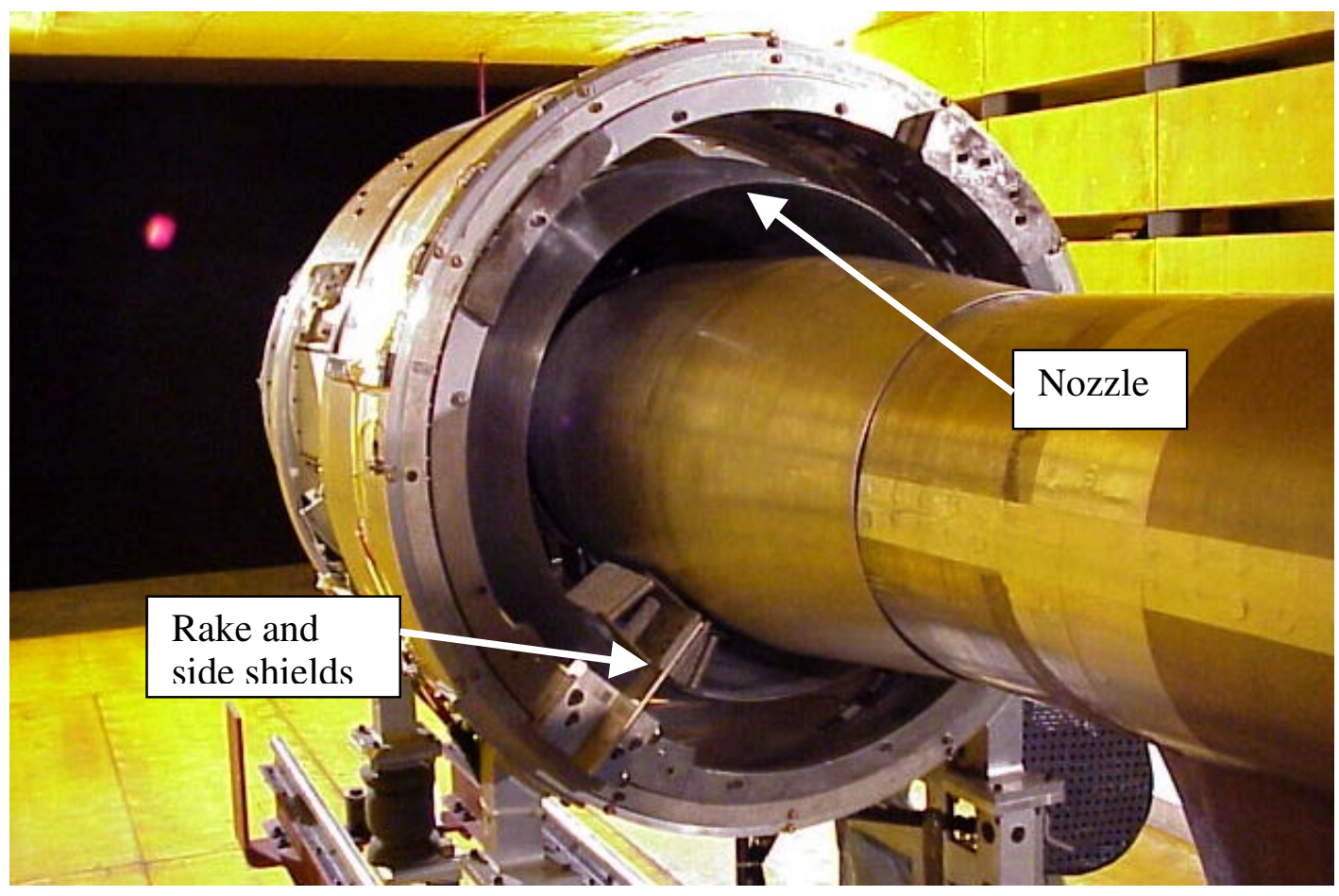

Figure 4. Mode measurement system installed of the exhaust. 


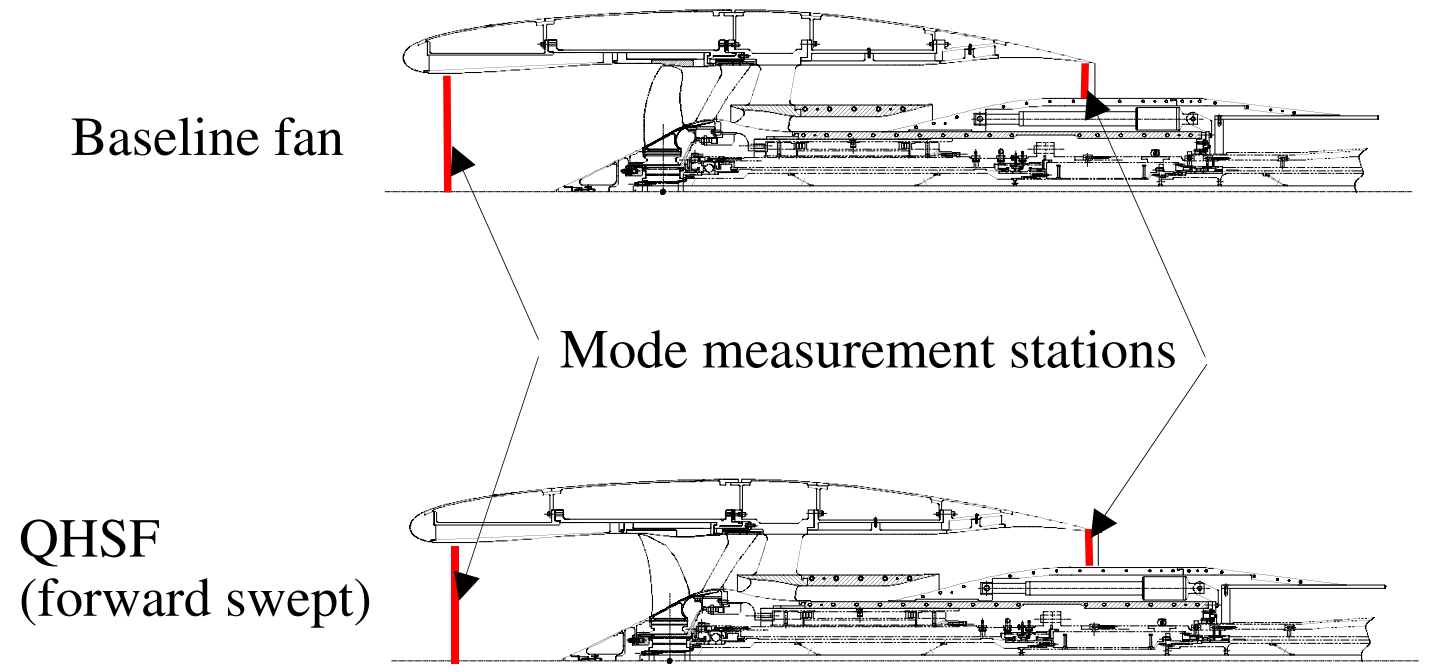

Figure 5. Fan model cross sections showing mode measurement stations.

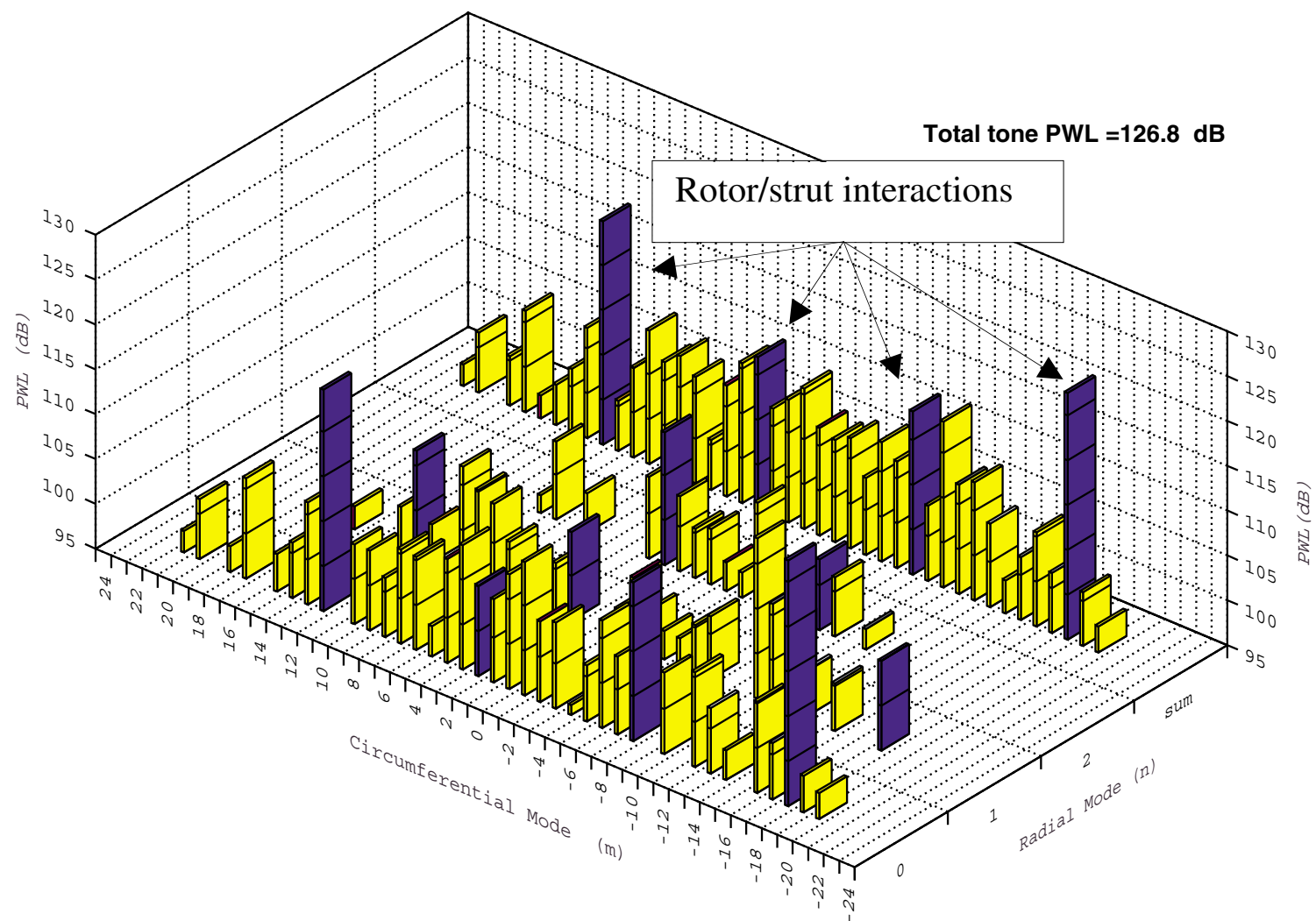

Figure 6. Modal structure for the baseline fan in the exhaust at BPF, cutback power (11570 RPMc). 


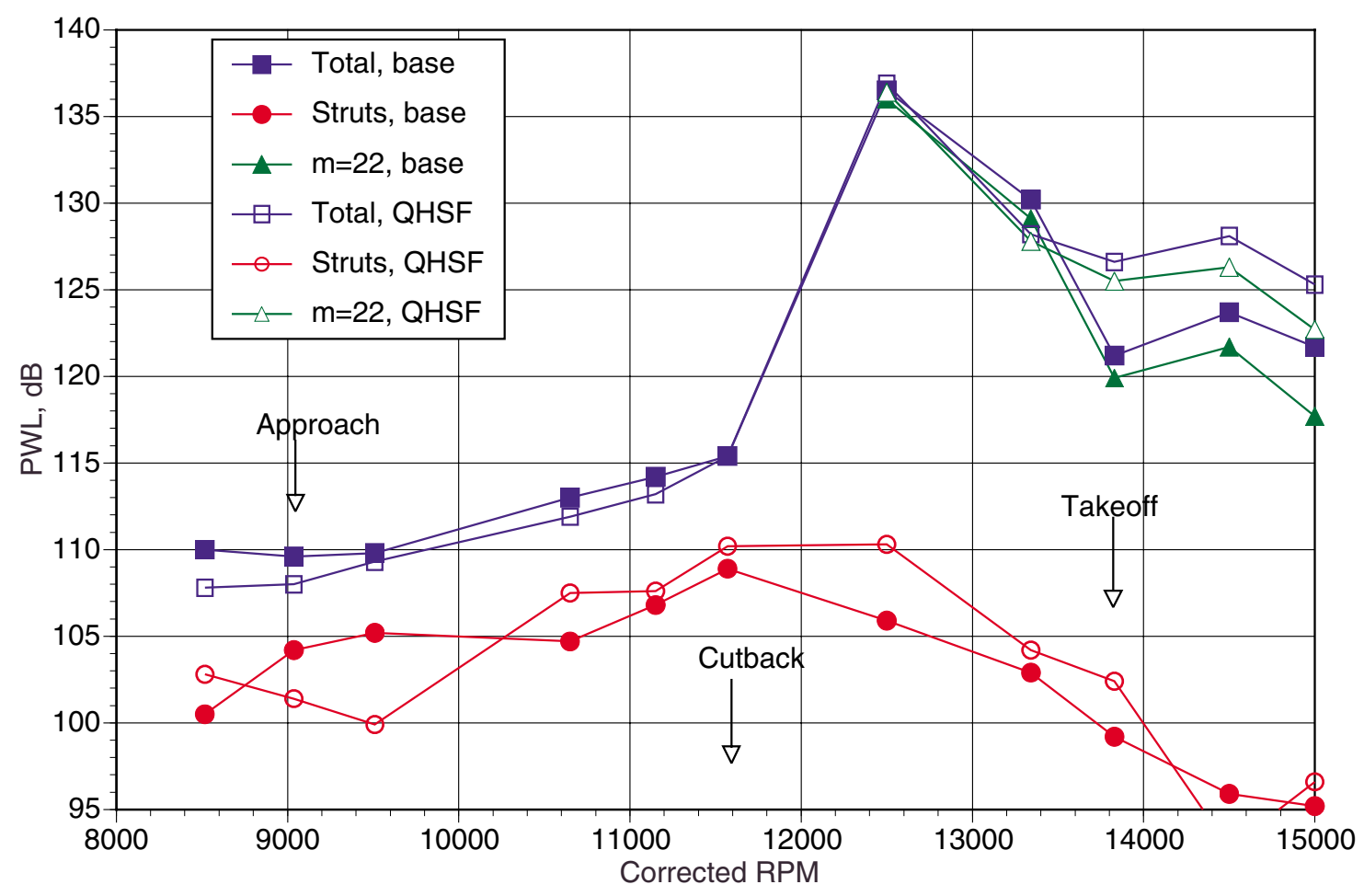

Figure 7. Comparison of the inlet modal power of the baseline fan to the QHSF at BPF.

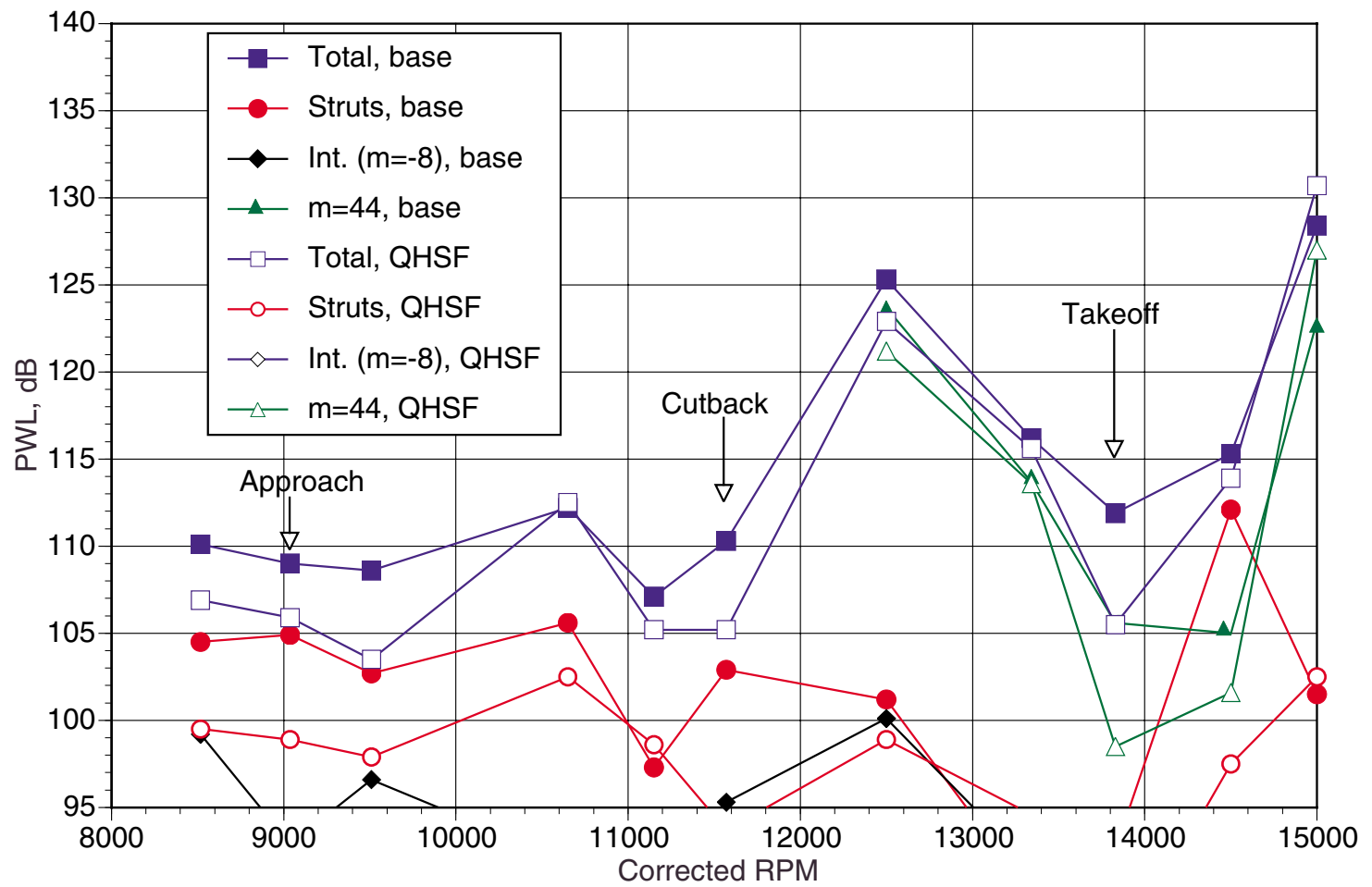

Figure 8. Comparison of the inlet modal power of the baseline fan to the QHSF at 2BPF. 


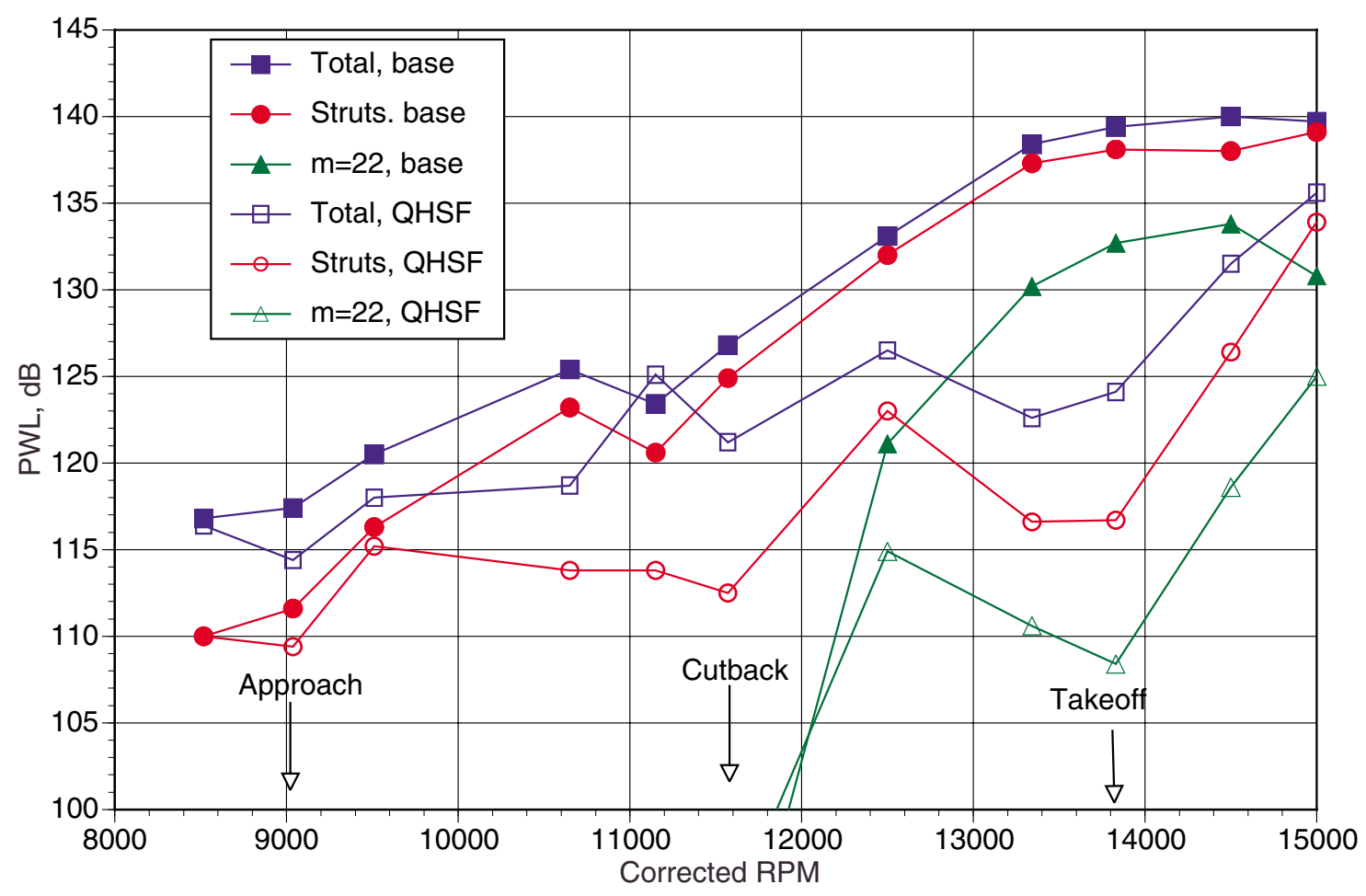

Figure 9. Comparison of the exhaust modal power of the baseline to the QHSF at BPF.

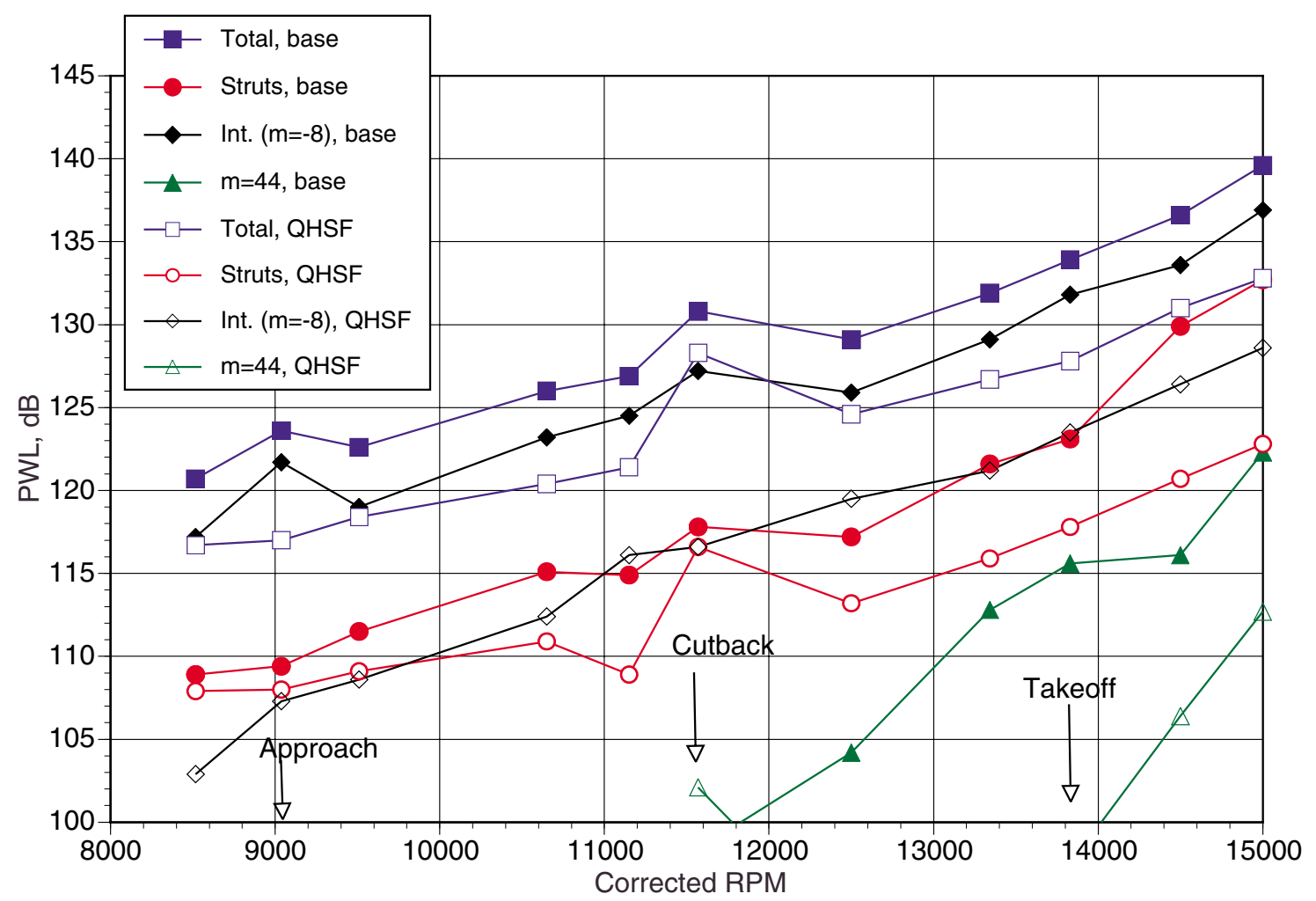

Figure 10. Comparison of the exhaust modal power of the baseline fan to the QHSF at 2BPF. 

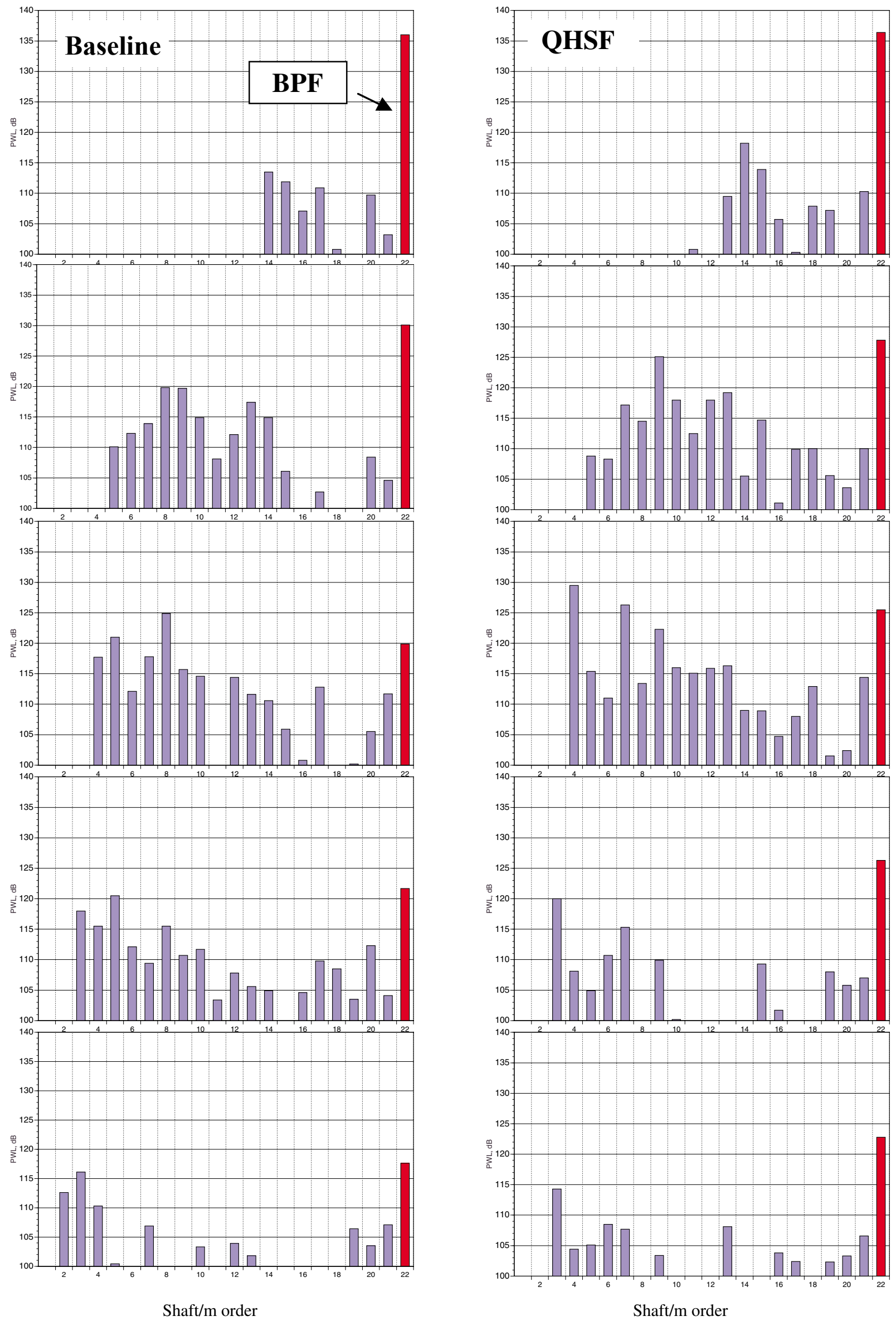

Figure 11. Comparison of MPT shaft order power distribution between the baseline and QHSF. 


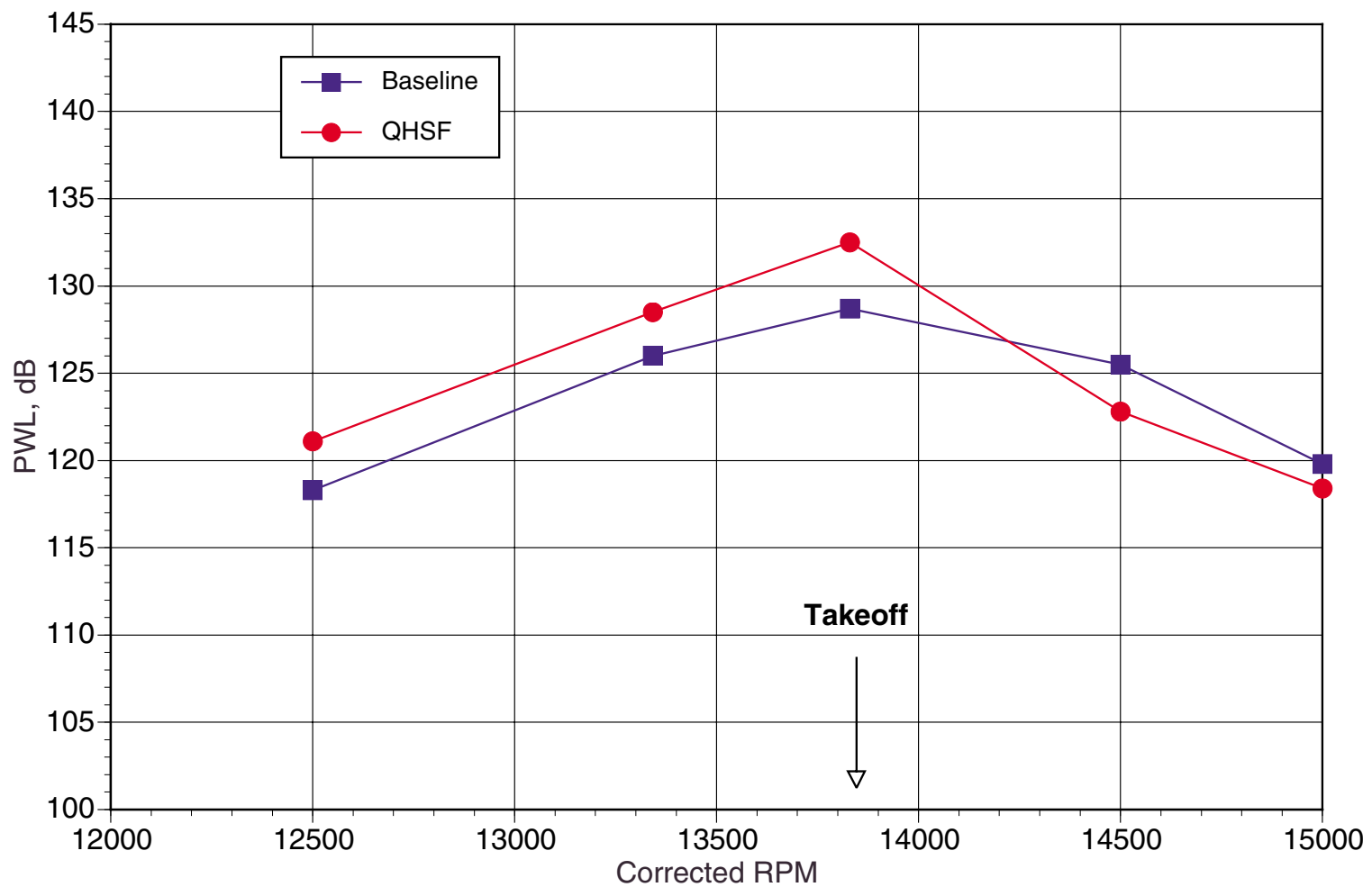

a) MPT power.

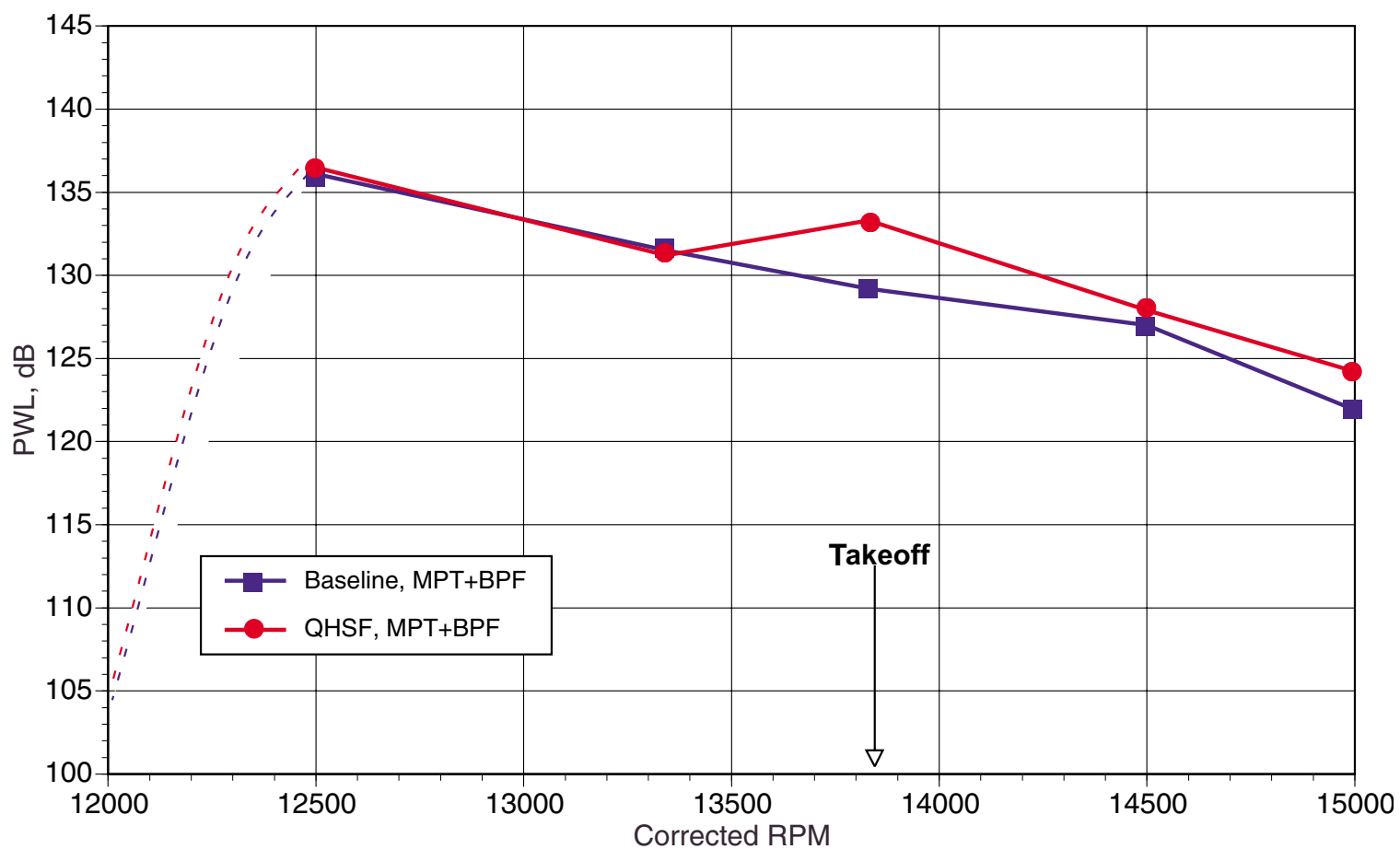

b) $\mathrm{MPT}+\mathrm{BPF}$ power.

Figure 12. Comparison of MPT power (sum of all cuton modes up to $\mathrm{m}=21$ ) and MPT plus BPF power for the baseline and QHSF. 

Public reporting burden for this collection of information is estimated to average 1 hour per response, including the time for reviewing instructions, searching existing data sources, gathering and maintaining the data needed, and completing and reviewing the collection of information. Send comments regarding this burden estimate or any other aspect of this collection of information, including suggestions for reducing this burden, to Washington Headquarters Services, Directorate for Information Operations and Reports, 1215 Jefferson Davis Highway, Suite 1204, Arlington, VA 22202-4302, and to the Office of Management and Budget, Paperwork Reduction Project (0704-0188), Washington, DC 20503.

\begin{tabular}{|l|l|l}
\hline 1. AGENCY USE ONLY (Leave blank) & $\begin{array}{c}\text { 2. REPORT DATE } \\
\text { June } 2003\end{array}$ & $\begin{array}{c}\text { 3. REPORT TYPE AND DATES COVERED } \\
\text { Technical Memorandum }\end{array}$
\end{tabular}

4. TITLE AND SUBTITLE

5. FUNDING NUMBERS

Comparison of Tone Mode Measurements for a Forward Swept and Baseline

Rotor Fan

6. AUTHOR(S)

Laurence J. Heidelberg

WBS-22-781-30-12

7. PERFORMING ORGANIZATION NAME(S) AND ADDRESS(ES)

National Aeronautics and Space Administration

John H. Glenn Research Center at Lewis Field

Cleveland, Ohio 44135-3191

8. PERFORMING ORGANIZATION

REPORT NUMBER

E-13953

9. SPONSORING/MONITORING AGENCY NAME(S) AND ADDRESS(ES)

National Aeronautics and Space Administration

Washington, DC 20546-0001

10. SPONSORING/MONITORING

AGENCY REPORT NUMBER

NASA TM-2003-212378

AIAA-2003-3293

\section{SUPPLEMENTARY NOTES}

Prepared for the Nineth Aeroacoustics Conference and Exhibit cosponsored by the American Institute of Aeronautics and Astronautics and the Confederation of European Aerospace Societies, Hilton Head, South Carolina, May 12-14, 2003. Responsible person, Laurence J. Heidelberg, organization code 5940, 216-433-3859.

12a. DISTRIBUTION/AVAILABILITY STATEMENT

12b. DISTRIBUTION CODE

Unclassified - Unlimited

Subject Category: 01

Distribution: Nonstandard

Available electronically at http://gltrs.grc.nasa.gov

This publication is available from the NASA Center for AeroSpace Information, 301-621-0390.

13. ABSTRACT (Maximum 200 words)

A forward swept fan, designated the Quite High Speed Fan (QHSF), was tested in the NASA Glenn 9- by 15-foot Low Speed Wind Tunnel to investigate its noise reduction relative to a baseline fan of the same aerodynamic performance.

The design objective of the QHSF was a $6 \mathrm{~dB}$ reduction in Effective Perceived Noise Level relative to the baseline fan at the takeoff condition. The design noise reduction was to be a result of lower levels of multiple pure tone noise due to the forward swept rotor, and lower rotor/stator interaction tone noise from a leaned stator. Although the design $6 \mathrm{~dB}$ reduction was observed in far-field measurements, the induct mode measurements revealed the reasons for this reduction were not the ones related to the design goals. All of the noise reduction was from the blade passing tone and its harmonics and most of this was unexpectedly from rotor/strut interaction modes. The reason for large differences in rotor/strut noise sources could not be determined with certainty. The reductions in the multiple pure tone noise for the forward swept rotor were not observed.

14. SUBJECT TERMS

Ducted fans; Propagation modes; Engine noise; Aeroacoustics

\begin{tabular}{|c|c|c|}
\hline $\begin{array}{c}\text { 17. SECURITY CLASSIFICATION } \\
\text { OF REPORT } \\
\text { Unclassified }\end{array}$ & $\begin{array}{c}\text { 18. SECURITY CLASSIFICATION } \\
\text { OF THIS PAGE } \\
\text { Unclassified }\end{array}$ & $\begin{array}{c}\text { 19. SECURITY CLASSIFICATION } \\
\text { OF ABSTRACT } \\
\text { Unclassified }\end{array}$ \\
\hline
\end{tabular}

NSN 7540-01-280-5500

Standard Form 298 (Rev. 2-89)

Prescribed by ANSI Std. Z39-18 298-102 